\title{
Correction to: Do exchange rate changes have threshold effects on the trade balance? Evidence from Tunisia
}

\section{Makrem Ben Doudou ${ }^{1}$ (D) $\cdot$ Ridha Nouira $^{1} \cdot$ Sami Saafi ${ }^{1} \cdot$ Aram Belhadj $^{2}$}

Published online: 5 November 2020

(c) Springer Science+Business Media, LLC, part of Springer Nature 2020

\section{Correction to: Economic Change and Restructuring https://doi.org/10.1007/s10644-020-09306-4}

In the original publication of the article, abstract section contains errors.

The second line of abstract "Different from previous studies" should be read as "Unlike previous works".

The seventh line of abstract "and 17 of its major trade partners over the period 1984-2016" should be read as "and 17 of its major trading partners over the period 1991-2019".

The eighth line of abstract "confirm a non-linear relationship" should be read as "confirm the existence of a nonlinear relationship".

Publisher's Note Springer Nature remains neutral with regard to jurisdictional claims in published maps and institutional affiliations.

The original article can be found online at https://doi.org/10.1007/s10644-020-09306-4.

Makrem Ben Doudou

m_bendoudou@yahoo.fr

1 EAS-Faculty of Economic Sciences and Management of Mahdia, University of Monastir, Hiboun Cité Sidi Messaoud, 5111 Mahdia, Tunisia

2 Faculty of Economics and Management of Nabeul, LR18ES48, ENVIE, University of Carthage, Nabeul, Tunisia 